\title{
Information effects on the response-reinforcer association
}

\author{
BEN A. WILLIAMS \\ University of California, San Diego, La Jolla, California 92093
}

\begin{abstract}
Pigeons were trained on a discrete-trial delayed reinforcement procedure with respect to one response key that was periodically illuminated. In some conditions, a second response key, or a tone, both previously paired with reinforcement, was interpolated in the delay-ofreinforcement interval. In comparison to a control condition with neither stimulus in the delay interval, the interpolated stimulus attenuated (blocked) the amount of responding that was maintained by the delayed reinforcement contingency. The degree of blocking was unaffected by whether the interpolated stimulus was the tone or keylight, in spite of the fact that the keylight evoked responding and the tone did not. A second study showed that the blocking effects involved the response-reinforcer association in that blocking occurred when the delayed reinforcement was response-dependent but did not occur when reinforcement was responseindependent. The results thus show that response-reinforcer associations are affected by informational variables in the same manner as has been shown for stimulus-reinforcer associations. They also demonstrate that preexisting stimulus-reinforcer associations can block response-reinforcer associations, thus suggesting that both types of association depend upon the same associative process.
\end{abstract}

Research during the past 10 years has shown that "informational" variables are an important determinant of whether conditioning will occlir. Perhaps the simplest, and most compelling, demonstration of an informational effect is the phenomenon of "blocking " (cf. Kamin, 1969). The typical procedure for producing blocking is to pair some compound stimulus (AB) with reinforcement. Normally, both elements gain stimulus control, as shown when they are tested separately. If pretraining is given with one of the elements (A) alone, however, acquisition of stimulus control by the other element (B) during compound $\mathrm{AB}$ training is much weaker. Thus, pretraining with A blocks control by $\mathrm{B}$. The importance of the finding is its demonstration that temporal contiguity between element $B$ and the reinforcer is not sufficient to cause conditioning to occur. Instead, the stimulus also must provide information about the occurrence of the reinforcer that is not already provided by other events in the situation.

The process underlying information effects like blocking currently is a matter of dispute (cf. Mackintosh, 1975). The experiments to be reported are not concerned with this theoretical issue, however, but instead are addressed to defining the domain over which blocking effects occur. More specifically, do informational variables determine the effects of

This research was supported by NSF Grant GB-42877. Reprint requests should be sent to the author, Department of Psychology C-009, University of California, San Diego, La Jolla, California 92093. response-contingent reinforcement in the same way they have been shown to determine stimulus-selection effects found with classical conditioning and discrimination learning? This question is relevant to the issue of whether classical and operant conditioning procedures obey similar principles and, consequently, whether classical and operant conditioning should be regarded as separate conditioning processes. If the effects of informational variables in different conditioning procedures can be shown to be equivalent, and possibly interchangeable, the possibility that the same associative processes determine the outcomes of both conditioning procedures becomes more likely.

There is major procedural difficulty inherent in any demonstration of blocking of the responsereinforcer association. Demonstrations of blocking involving stimulus-reinforcer associations have presented the pretrained and novel element simultaneously as a compound stimulus. Such simultaneous presentation is impossible for operant situations, however, because the schedule of presentation of the pretrained element is determined by the occurrence of the operant response, and thus cannot occur until after the response. Moreover, to the extent that the pretrained stimulus possesses conditioned reinforcement properties, its presentation contingent on the operant response may produce a responsestrengthening effect acting in the opposite direction of blocking.

In spite of these difficulties, Williams (1975) has presented evidence suggesting that blocking of response-reinforcer associations may occur. He com- 
pared the effects of a delay-of-reinforcement procedure, with or without a previously conditioned response evoked in the delay interval. When the previously conditioned response occurred, the degree of responding maintained by the delayed reinforcement contingency was reduced.

Although the results of Williams (1975) are suggestive, their interpretation is ambiguous because it is unclear whether the association underlying the responding was between the stimulus and reinforcer or between the response and reinforcer. That is, a discrete-trial procedure was used in which presentations of the keylight associated with the delayed reinforcement contingency were separated by substantial intertrial intervals. It is thus possible that at least some of the behavior that occurred to the keylight was due to the stimulus-reinforcer contingency, i.e., autoshaping effects, and thus did not depend upon the response contingency. Accordingly, the blocking effect that was observed might have been only another instance of the blocking of stimulus control and thus have little generality for other instrumental conditioning situations in which stimulusreinforcer contingencies are of less importance. A resolution of this issue requires a more complete investigation of the response contingency in maintaining the behavior that was observed.

A second issue raised by the results of Williams (1975) is the nature of the events necessary to cause blocking. The previous procedure interpolated a second keylight during the delay-of-reinforcement interval to which a second pecking response had been conditioned previously. The question is whether blocking depended upon the occurrence of a second instrumental response just prior to the reinforcer or whether the presentation of the stimulus itself was sufficient, regardless of the actual behavior that it controlled. Since the presumed basis of blocking is that conditioning does not occur when the reinforcer is already "predicted" by other events in the situation, the underlying issue is whether stimulus-reinforcer associations are interchangeable with responsereinforcer associations in determining the degree to which the reinforcer is predicted. This issue can be addressed by examining whether the blocking effects obtained in the delay-of-reinforcement procedure used by Williams (1975) varies with whether the stimulus interpolated in the delay interval does or does not evoke an instrumental response.

\section{EXPERIMENT 1}

The major goal of Experiment 1 was to replicate the main effect of Williams (1975) with a slightly different procedure. The procedure differed from the previous study in the method used to maintain responding to the stimulus interpolated in the delay- of-reinforcement interval. Whereas the earlier study relied on pretraining with respect to the interpolated response, the present study included a concurrently maintained discrimination where the interpolated stimulus served as $\mathbf{S}+$. It was hoped that such a procedure would maintain the strength of the interpolated response at a consistently high level and thus reduce the considerable variability found in the previous study.

A second issue addressed by Experiment 1 was whether the location of the interpolated stimulus in the delay-of-reinforcement interval was a significant variable. One group of subjects received the same procedure as Williams (1975) in which the interpolated stimulus was presented just prior to the delivery of the reinforcer. For a second group, the interpolated stimulus was presented earlier in the delay interval and terminated before the presentation of the reinforcer.

\section{Method}

Subjects. Twelve White Carneaux pigeons were maintained at $80 \%$ of their free-feeding body weights by additional feeding, if necessary, at the end of an experimental session. All had served in a previous autoshaping experiment in a different apparatus with different stimuli.

Apparatus. Two identical two-key pigeon conditioning chambers were constructed from plastic picnic chests. The chamber was $30.5 \mathrm{~cm}$ in all dimensions. On the front panel were mounted two transparent keys, $1.6 \mathrm{~cm}$ in diameter, which required a force of at least $0.10-0.12 \mathrm{~N}$ for operation. The stimuli were projected on the rear of the keys by standard $28-\mathrm{V}$ dc, 12-stimulus in-line projectors. Ten centimeters below the keys was a $5 \times 5 \mathrm{~cm}$ aperture through which the birds were fed when the grain magazine was operated. Located on the rear wall of the inner chamber was a $28-\mathrm{V}$ dc houselight that was illuminated at all times during an experimental session.

Procedure. The subjects were first trained under an autoshaping procedure. The left key was illuminated for $5 \mathrm{sec}$ with a diffuse green light, followed by a 3 -sec access to the grain magazine. Fifty trials were presented, separated by a 50 -sec ITI. Since all subjects had served in a previous autoshaping experiment, all pecked consistently during the first session. The second and third sessions involved an identical autoshaping procedure but using the right key, which was illuminated with a $45^{\circ}$ red line projected on a dark background. The fourth session again involved only the left key but with a response contingency. It was illuminated for $5 \mathrm{sec}$ with a green light, followed by a 3-sec delay with no keylight on, and the reinforcer if at least one peck had occurred to the left key during its illumination.

After pretraining, the subjects were randomly assigned to the three experimental groups. All subjects received three different types of trials, randomly interspersed and separated by a $30-\mathrm{sec}$ ITI, for a total of 80 trials per session. Forty of the trials involved a maintained discrimination between two stimuli projected on the right key. For 20 trials, the $45^{\circ}$ red line $(\mathrm{S}+)$ was presented for $5 \mathrm{sec}$, followed immediately by food if at least one peck had occurred. For the other 20 triais, a vertical white ine $(S-)$ was presented for $5 \mathrm{sec}$ but was never followed by food. The remaining 40 trials involved a delayed-reinforcement contingency with respect to the left key. For all subjects, the left key was illuminated for $5 \mathrm{sec}$ with green light, followed by a 10 -sec delay and then the grain reinforcer if at least one peck had occurred. The three experimental groups were defined by the events that occurred during the delay-of-reinforcement interval. For Group L/10, the 


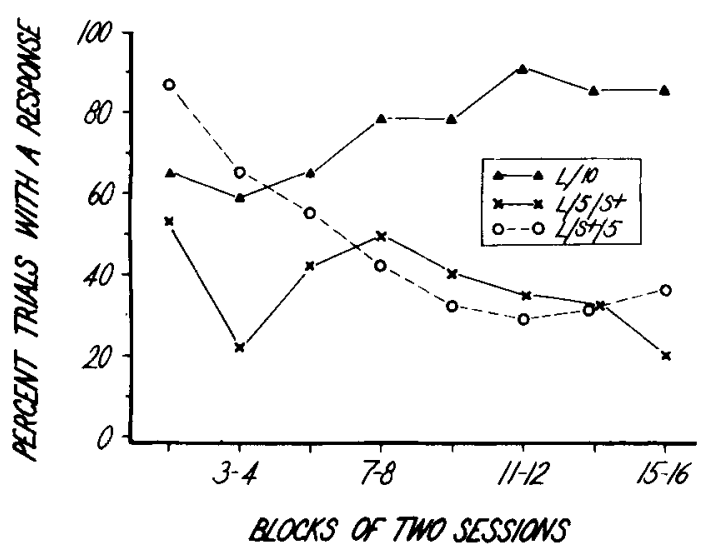

Figure 1. Mean percentage of trials with a response to the left key during Experiment 1.

right key was never illuminated during the 10 -sec delay. For Group $\mathrm{L} / 5 / \mathrm{S}+$, the offset of the left green key was followed by a 5 -sec delay and then the illumination of the right key for $5 \mathrm{sec}$ with the $\mathrm{S}+$. And for Group L/S + $/ 5$, the left key offset was followed immediately by the illumination of the right key for $5 \mathrm{sec}$ with the $\mathrm{S}+$ and a 5 -sec delay before delivery of the reinforcer. The stimulus condition during the delay-of-reinforcement interval was the same as during the intertrial interval. Responding to the interpolated right key during the delay interval was recorded but had no scheduled effect.

\section{Results and Discussion}

Figure 1 shows the group means for the percentage of trials with a response to the left green key. Consistent responding was maintained only by Group $\mathrm{L} / 10$ which did not have the right key illuminated during the delay-of-reinforcement interval. Responding in the other two groups gradually declined to the same level over the 16 sessions of training. The results were analyzed by blocking the sessions into groups of four and subjecting the data to a two-way analysis of variance (Groups by Blocks). Neither Groups $[F(2,29)=2.38, p>.05]$ nor Blocks $[F(3,27)=1.11$, $\mathrm{p}>.05$ ] was statistically significant. The interaction between the variables was significant $[\mathrm{F}(6,27)=5.46$, $\mathrm{p}<.05$ ]. Consequently, a one-way analysis of variance was performed on the data from the last four sessions of training. This, too, was significant $[F(2,9)$ $=5.78, \mathrm{p}<.05]$, establishing that the experimental conditions maintained different behavior by the end of training.

The major individual comparison of interest was that between Groups $\mathrm{L} / \mathrm{S}+/ 5$ and $\mathrm{L} / 5 / \mathrm{S}+$, which differed only in terms of the location of the interpolated right key during the delay interval. Although the two groups did produce similar levels of responding by the end of training, there was considerably more responding by Group $\mathrm{L} / \mathrm{S}+/ 5$ for the first several sessions. This difference was statistically reliable, as indicated by a $t$ test on the first two sessions of training $[\mathrm{T}(6)=2.64, \mathrm{p}<.05]$.
Group L/S + /5 initially produced greater left-key responding than Group $\mathrm{L} / 10$, but the difference, as assessed by a $t$ test on responding during the first session, was not statistically significant $[\mathrm{t}(6)=2.10$, $.10>\mathrm{p}>.05]$.

Although (at the end of training) Groups $\mathrm{L} / 5 / \mathrm{S}+$ and $\mathrm{L} / \mathrm{S}+15$ did not differ in the rate of responding to the left key, there was some evidence of a difference for responding to the $\mathrm{S}+$ itself, both when it was interpolated in the delay interval and when it was presented alone. Table 1 shows the behavior to the $\mathrm{S}+$ for the different groups during the last four sessions of training. Group $\mathrm{L} / 5 / \mathrm{S}+$ maintained a higher rate than either of the other two conditions, under both types of $\mathrm{S}+$ presentations. The differences with respect to rate of responding were not statistically significant because of great within-group variability with regard to that measure. The difference in the percent-trials measure also was not significant when the $\mathrm{S}+$ was presented alone, but was significant when the $\mathrm{S}+$ was interpolated in the delay interval $[t(6)=4.10, p<.05]$. The groups did not differ in responding to the $S$ - alone, as the mean rate of $S$ responding was less than $1 / \mathrm{min}$ for all three groups.

The fact that Groups $\mathrm{L} / 5 / \mathrm{S}+$ and $\mathrm{L} / \mathrm{S}+/ 5$ produced essentially similar behavior by the end of training suggests that the necessary condition for "blocking" with the present procedure is that some type of interfering response occurs somewhere in the delay interval. This possibility was first suggested by Spence (1956), who described several experiments where the responding maintained by a delayed reinforcement contingency was inversely related to whether interfering behavior occurred in the delay interval. Although such a possibility cannot be excluded on the basis of the present data alone, Experiment 2 of Williams (1975) did provide evidence against such an interpretation. For one condition of that experiment, the subjects received essentially the same procedure as the $\mathrm{L} / 5 / \mathrm{S}+$ group of the present study. For a second group, the same stimulus was again presented in the delay interval but was not paired with reinforcement outside of the delay

Table 1

Responding to the $S+$ When Interpolated in the Delay-of-Reinforcement Interval and When Presented Alone

\begin{tabular}{lccccc}
\hline & \multicolumn{2}{c}{ S+ in Delay } & & \multicolumn{2}{c}{ S+ Alone } \\
\cline { 2 - 3 } \cline { 5 - 6 } Group & $\begin{array}{c}\text { Percent } \\
\text { Trials }\end{array}$ & Rate & & $\begin{array}{c}\text { Percent } \\
\text { Trials }\end{array}$ & Rate \\
\hline L/10 & & & 99 & 154 \\
L $/ 5 / S+$ & 98 & 246 & & 100 & 246 \\
L/S+/5 & 84 & 141 & & 96 & 192 \\
\hline
\end{tabular}

Note-Two measures are presented: percent trials with at least one response and the rate of responding (responses per minute). 
interval. The two conditions produced an equivalent amount of responding to the stimulus when it was presented during the delay interval, but blocking occurred only for the first condition. Thus, contrary to Spence's hypothesis, the reinforcement history of the interpolated stimulus, not whether it elicited responding, was the critical determinant of the blocking effect. The general similarity between Groups $\mathrm{L} / 5 / \mathrm{S}+$ and $\mathrm{L} / \mathrm{S}+/ 5$ demonstrates that the interpolated stimulus can cause blocking even when it does not immediately precede the onset of the reinforcer.

\section{EXPERIMENT 2}

The results of Experiment 1 leave unspecified the nature of the agent that produced blocking. That is, did the attenuation of the effects of the reinforcement contingency occur because a previously conditioned response preceded the delivery of the reinforcer, or was it due instead to the presentation of a stimulus that already predicted the occurrence of the reinforcer, quite apart from the response controlled by the stimulus? At one level of analysis the issue is untestable, since all responses are defined by their occurrence in some spatial framework and all stimuli paired with reinforcement will elicit at least some type of behavior. The issue may become meaningful, however, when it is considered in the context of the type of response. There now exists a substantial literature showing that the type of response affects a variety of conditioning phenomena, including avoidance learning (Foree \& Lolordo, 1970) and behavioral contrast (Hemmes, 1973; Westbrook, 1973). Such findings suggest that blocking might be affected by the type of response concurrently available preceding the reinforcer. Specifically, responses that are "prepared" for association with the reinforcer (e.g., keypecking for food with pigeons) may serve as a better agent to produce blocking than those not so prepared.

A related consideration is the type of stimulus. Lolordo, Jacobs, and Foree (Note 1) have reported that blocking in an appetitive conditioning situation depended upon the modality of the stimulus. Pretraining with light-food pairings blocked the later acquisition of tone-food association when tone and light were simultaneously compounded, but pretraining with tone did not block the later acquisition of control by light during the same compound stimulus training. Previous research has demonstrated that light was more likely to be associated with food, but not with shock, when both tone and light were simultaneously presented (Foree \& Lolordo, 1973). To the extent that blocking is affected either by the type of stimulus or by the type of response controlled by the stimulus, the effects of "preparedness"' should be evident in an instrumental conditioning situation like that of Experiment 1. To investigate this possibility, Experiment 2 compared the effects of two different positive stimuli, the keylight $\mathrm{S}+$ used in Experiment 1 and a new tonal stimulus.

\section{Method}

Subjects. Twelve White Carneaux pigeons were maintained at $80 \%$ of their free-feeding body weights by additional feeding, when necessary, after the end of the experimental sessions. All had previously served in a blocking study similar to Experiment 1.

Apparatus. The same apparatus was used as in Experiment 1, with the modification that a "Sonalert" tone generator (LVE/BRS Model 112-01) was mounted on the rear wall of each chamber. The input to the tone generator was $28-\mathrm{V}$ dc with a $12,000-\mathrm{ohm}$ resistor in series. The resulting signal was approximately $91 \mathrm{~dB}$ in intensity (SPL) as measured from the center of the chamber. Ambient noise level in the absence of the tone was $81 \mathrm{~dB}$.

Procedure. All subjects were trained in a preliminary experiment similar to Experiment 1, except that the stimulus used to cause blocking was presented prior to the instrumental response opportunity and reinforcement was immediately contingent on the instrumental response. During this training, all subjects were exposed to the same tone and keylight stimuli as were used in the procedure described below, so that the subjects had extensive experience with the tone and keylight $S+s$ ' being paired with noncontingent reinforcement. The results of the preliminary training are not presented in this paper.

After the preliminary training, the procedure was changed to include a delay-of-reinforcement contingency like that of Experiment 1 . Five seconds of the instrumental response opportunity (illumination of the left key with green light) was followed by a 10-sec delay interval and then the reinforcer if at least one response occurred during left-key illumination. Three conditions were studied, defined by the stimulus present during the last $5 \mathrm{sec}$ of the delay-of-reinforcement interval. For the tone condition, a 5 -sec tone burst was presented, which also served as an S+ on trials in which it was presented alone. For the keylight condition, a 5-sec illumination of the right key with an oblique red line was presented which also was paired with reinforcement on other trials. For the control condition, the entire 10-sec delay involved the same stimulus conditions as during the ITI (i.e., no keylights illuminated and no tones).

For all three conditions, a total of 100 trials was presented each session. Twenty-five involved the delay-of-reinforcement contingency with respect to the left key (these were "tone," "keylight," or "control" trials); 28 involved the presentation of either the tone $\mathrm{S}+$ or keylight $\mathrm{S}+$ (illumination of the right key) for $5 \mathrm{sec}$, followed by response-independent reinforcement; and 47 involved the presentation of an S-, which for all conditions was a 5-sec illumination of the right key with a white vertical line. To avoid running two separate control conditions, one-half of the subjects received the tone as $\mathrm{S}+$ (for $\mathrm{S}+$ alone trials) for the first five sessions of training and then received the keylight $S+$ for the second five sessions. The remaining subjects had the order of $\mathrm{S}+$ presentations during the control condition reversed.

A 30-sec ITI separated the trials in all conditions. Ten consecutive sessions of training on each condition were presented to all subjects, with the order of presentation of the three conditions counterbalanced across subjects.

\section{Results and Discussion}

Table 2 shows the data for the last two sessions of each condition. The control condition produced greater responding than both blocking conditions for both response measures, indicating that blocking did occur. The tone and keylight conditions did not 
Table 2

Responses per Minute and Percent Trials with a Response on the Left (Delayed Reinforcement) Key During the Last Two Sessions of Each Condition of Experiment 2

\begin{tabular}{ccc} 
Condition & Rate & $\begin{array}{c}\text { Percent } \\
\text { Trials }\end{array}$ \\
\hline Control & 40 & 67 \\
Tone & 20 & 40 \\
Keylight & 21 & 39 \\
\hline
\end{tabular}

differ, however, showing that the type of stimulus presented in the delay interval was irrelevant in determining the degree of blocking.

The data from the last two sessions were analyzed statistically by a one-way ANOVA on the trials-witha-response measure. The groups variable was significant $[F(2,22)=15.7, p<.05]$, as was the subsequent comparison of the control condition with the mean of the two blocking conditions $[t(11)=4.85$, $\mathrm{p}<.05$ ]. A comparison of the two blocking conditions was not significant $(t<1.0)$.

Figure 2 shows the development of the differences across sessions. The two blocking conditions were highly similar at all stages of training, while the control condition was initially lower (because training on the control condition always followed training on a blocking condition) and then increased.

A final aspect of the results was the behavior during presentations of the $\mathrm{S}+$, both within and outside of the delay-of-reinforcement interval. The keylight maintained a high rate of responding for all subjects, whereas the tone did not. Three of the 12 subjects showed some pecking during the tone (rate $>5$ responses $/ \mathrm{min}$ ) but there was no relation between the likelihood of such pecking and whether blocking occurred. In addition, observation of the subjects revealed no consistent pecking behavior to aspects of the experimental chamber other than the keylights.

The results established that the blocking effects obtained with the instrumental reinforcement contingency did not depend upon the type of stimulus used as the $\mathrm{S}+$. The results also showed that blocking did not depend upon the occurrence of any particular type of response to the $S+$, since the magnitude of the effect obtained with the keylight and tone conditions was generally similar, and the keylight $\mathrm{S}+$ elicited pecking behavior and the tone $\mathrm{S}+$ did not. This does not mean that blocking occurred in the absence of any response to the $\mathrm{S}+$, because some type of behavior to the tone probably did occur. Given that the dimensions of that behavior were different from keypecking, however, and unmeasured, the best characterization of the conditions that produce blocking is simply that the reinforcer is predicted by other stimuli in the situation.
The similarity of the blocking effects caused by the keylight and tone $\mathrm{S}+\mathrm{s}$ is consistent with the findings of Allaway (described by Schwartz \& Gamzu, 1977) but inconsistent with the results of Lolordo et al. (Note 1). In Allaway's study, naive pigeons were presented an autoshaping procedure in which a tone was presented $2 \mathrm{sec}$ prior to a keylight presentation and then overlapped with the keylight for $6 \mathrm{sec}$ prior to the reinforcer delivery. In comparison to a keylightonly condition, much less autoshaped pecking occurred. The present results are similar to Allaway's except that the maintenance of pecking, not its acquisition, was studied, and the tone stimulus and the keylight were never presented simultaneously.

The discrepancy with the results of Lolordo et al. (Note 1) could be due to several factors. Several major differences exist in the procedures of their and the present study, including the nature of the auditory and visual stimuli, the type of instrumental response required (treadle-pressing vs. pecking), and the use of simultaneous vs. sequential stimulus compounds. It should be noted, however, that the occurrence of blocking with tone as the pretrained stimulus in the present study questions the generality of the "preparedness" notion supported by Lolordo et al.

\section{EXPERIMENT 3}

Experiment 2 demonstrated that the responsereinforcer association could be blocked by the concurrent presentation of a stimulus associated with reinforcement, even when that stimulus itself did not elicit pecking behavior. This implies that the blocking effect did not depend upon the occurrence of the instrumental response as the agent of blocking.

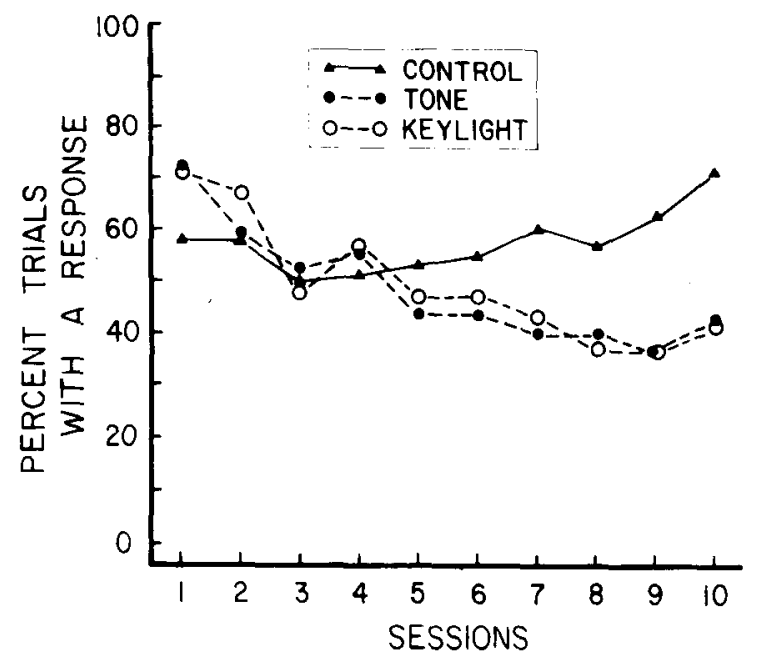

Figure 2. Mean percentage of trials with a response to the left key during Experiment 2. 
Instead, the rate of responding maintained by the instrumental reinforcement contingency was reduced by the presentation in the same temporal context of a stimulus positively associated with reinforcement.

The above discussion assumes that the responsereinforcer association was the learning experience attenuated by the blocking manipulation. This assumption is based on the fact that the reinforcer was delivered in the above experiments only if an instrumental response occurred. It is possible, however, that the response contingency was incidental to the actual maintenance of the observed behavior. This is suggested by autoshaping research using similar keypecking situations where the stimulusreinforcer contingency, not the response-reinforcer contingency, has been shown to be the primary controlling variable (Hearst \& Jenkins, 1974; Moore, 1973; Williams \& Williams, 1969). To the extent that the response requirement was not an important element of the above experiments, they lose much of their theoretical implication. The main purpose of the experiments was to determine whether responsereinforcer contingencies obeyed the same functional relations as stimulus-reinforcer contingencies. It is important, therefore, to establish the role of the response contingency in the keypecking situation used in the earlier experiments.

Experiment 3 assessed the role of the responsereinforcer contingency by comparing the effects of the blocking procedure used in Experiments 1 and 2 with response-dependent vs. response-independent reinforcement. A two-by-two comparison was made with response-dependent vs. response-independent reinforcement as one variable and the control vs. blocking condition as the other variable.

\section{Method}

The subjects were eight White Carneaux pigeons maintained at $80 \%$ of their free-feeding weights. All had served as subjects in a free-operant schedule experiment involving VI schedules (using different stimuli than the present study), but none had served in any previous blocking studies.

On the first day of training, all subjects were exposed to an autoshaping procedure in which 5-sec illuminations of the left key with green light were followed by $3 \mathrm{sec}$ access to the reinforcer. Forty trials were presented, separated by a 50 -sec ITI. The second day of training was exactly like the first, except that the houselight was not illuminated.

After the pretraining period, the procedure was changed to a discrete-trial procedure similar to that used in Experiments 1 and 2. However, two changes were made to minimize the role of the stimulus-reinforcer contingency in maintaining responding: (1) the ITI was shortened to $5 \mathrm{sec}$, and (2) no houselight was used. A total of 250 trials was presented each session: 24 involved the left-green key with the 10-sec delayed reinforcement contingency, 24 involved presentations of the same tone $\mathrm{S}+$ used in Experiment 2 , followed by response-independent reinforcement, and the remaining trials involved presentation of the white-line $\mathrm{S}$ - (on the right key) that was used in Experiments 1 and 2.

Four experimental conditions were defined by the events that occurred on trials involving the left-key delayed-reinforcement contingency. For the blocking/response-independent condition, the last $5 \mathrm{sec}$ of the delay-of-reinforcement interval included the presentation of the tonal $\mathrm{S}+$, and the reinforcer was delivered at the tone's termination regardless of whether the subject had pecked during the 5-sec illumination of the left-green key. For the blocking/response-dependent condition, the same procedure occurred except that the reinforcer was delivered only if at least one peck had occurred to the left key during its illumination. For the control/response-independent condition, the entire 10 -sec delay-of-reinforcement interval had the same stimulus conditions as the ITI and the reinforcer was always delivered at the end of the delay interval. Finally, for the control/response-dependent condition, the same procedure occurred except that the reinforcer was delivered only if at least one peck to the illuminated left key had occurred.

All subjects were presented 12 consecutive sessions of training on each of the four experimental conditions. Following the termination of training on each condition, two sessions, using the autoshaping procedure described above, were presented in order to increase the level of responding to the left key. The houselight was illuminated in the first autoshaping session but not in the second. The order of presentation of the four conditions was counterbalanced across subjects.

\section{Results and Discussion}

Table 3 shows the rate of responding and the percent trials with at least one response for the last four sessions of each condition. For both measures, the highest rate of responding occurred with the control/response-dependent condition. The two blocking conditions were intermediate, with the response-independent condition producing the least behavior.

The mean differences shown in Table 3 were tested statistically by a two-way ANOVA (Reinforcement Contingency by Blocking/Control) on the percenttrials measure. The blocking/control variable was not significant $(F<1.0)$, but the effects of reinforcement contingency were significant $[F(1,7)=19.57$, $\mathrm{p}<.05]$. The interaction between the two variables was also significant $[F(1,7)=6.01, p<.05]$, indicating that the blocking procedure reduced responding only when reinforcement was response-dependent.

A similar analysis on the response rate data showed that the blocking/control variable was again not significant $(\mathrm{F}<1.0)$ while the effect of the reinforcement contingency was significant $[F(1,7)=$

Table 3

Responses per Minute and Percent Trials with a Response on the Left Key During the Last Four Sessions of Each Condition of Experiment 3

\begin{tabular}{lccccc}
\hline & \multicolumn{2}{c}{$\begin{array}{c}\text { Response- } \\
\text { Independent }\end{array}$} & & \multicolumn{2}{c}{$\begin{array}{c}\text { Response- } \\
\text { Dependent }\end{array}$} \\
\cline { 2 - 3 } \cline { 5 - 6 } $\begin{array}{c}\text { Experimental } \\
\text { Condition }\end{array}$ & Rate & $\begin{array}{c}\text { Percent } \\
\text { Trials }\end{array}$ & & Rate & $\begin{array}{c}\text { Percent } \\
\text { Trials }\end{array}$ \\
\hline Control & 7.3 & 24.6 & 33.0 & 70.4 \\
Blocking & 13.4 & 40.5 & & 26.7 & 56.4 \\
\hline
\end{tabular}

Note-All subjects were exposed to all conditions. 
$14.28, \mathrm{p}<.05]$. With the rate analysis, however, the interaction was not significant $[F(1,7)=2.19, p>$ $.05]$. It should be noted that the rate measure was generally more variable for Experiments 1 and 2 as well.

Figure 3 shows the behavior maintained by the four conditions across the 12 sessions of training. The differences among the conditions gradually increased with continued training. To be noted is that behavior maintained by the control/responsedependent condition increased over sessions, whereas that maintained by the control/response-independent condition decreased. This strongly suggests that the response-reinforcer association is a necessary ingredient for the maintenance of behavior with the delay-of-reinforcement procedure used in the present series of studies and in Williams (1975).

The pattern of results demonstrates that the blocking effects produced by the tone $\mathrm{S}+$ interpolated in the delay-of-reinforcement interval occurred only when responding was maintained by responsedependent reinforcement. When reinforcement was delivered independently of responding, no blocking effect was found. This is not to say that the present blocking procedure would not also work with response-independent reinforcement if different procedural parameters had been employed. The conditions of the present study were chosen deliberately to minimize the behavior maintained by the stimulusreinforcer contingency, and so, not surprisingly, relatively little behavior was maintained by the control/ response-independent condition. It might have been expected that the interpolated $\mathrm{S}+$ in the blocking/ response-independent condition should have reduced

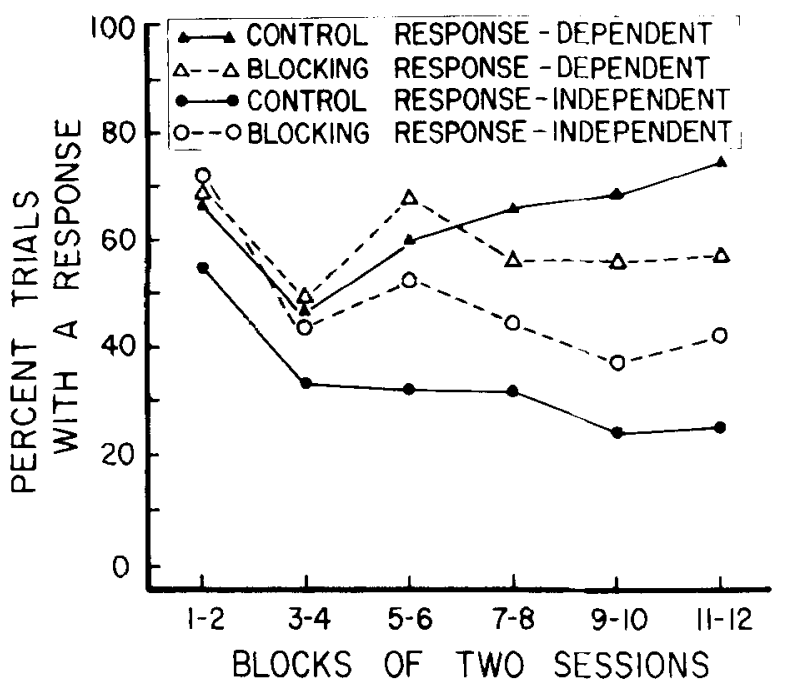

Figure 3. Mean percentage of trials with a response to the left key during Experiment 3. the behavior still further. Why this effect did not occur is uncertain.

It can be argued that the reduction in responding caused by the tone interpolated in the delay interval was not dependent on the tone-food association. To demonstrate the role of the tone-food association, it would be necessary to include a second control condition in which the tone was presented in the delay interval but not paired with reinforcement otherwise. It should be noted, however, that such a control procedure would be of interest only to the extent that the tone was not associated with the reinforcer during the delayed-reinforcement trials themselves. Such association should, in fact, be expected, since the blocking effects obtained with the present procedure were evident only after several sessions so that a large number of tone-food pairings would have occurred before any blocking effect could be observed. It also should be noted that previous research (Williams, 1975) has shown that the blocking effect obtained with the present delayedreinforcement procedure does depend upon the association of the interpolated stimulus with reinforcement.

\section{GENERAL DISCUSSION}

Two major effects were demonstrated by the present series of experiments: (1) the degree of blocking was unaffected by the type of stimulus used as the interpolated $\mathrm{S}+$ (and by the behavior evoked by the interpolated $S+$ ), in that the tone $S+$ was as effective in producing blocking as the keylight $\mathrm{S}+$; (2) the blocking effects involved attenuation of the response-reinforcer association, in that blocking occurred in Experiment 3 only when an instrumental response requirement was employed.

The second effect is perhaps of greatest interest because it shows that blocking extends to operant learning situations involving response-dependent reinforcement. It is now evident for both classical and operant conditioning that temporal relations between conditioning elements (stimulus and reinforcer or response and reinforcer) are not in themselves sufficient to predict when conditioning will occur. An additional consideration is whether the element preceding the reinforcer uniquely predicts the occurrence of the reinforcer. That is, conditioning is less likely to occur when other stimuli, previously associated with the reinforcer, also precede the reinforcer's occurrence.

Support for the generality of blocking effects for instrumental learning also comes from a recent series of simple discrimination experiments with rats (Fowler, in press; Fowler, Goodman, \& Zanich, 1977; Ghiselli \& Fowler, 1976). In one experiment (Fowler, 
in press) rats were first trained on a classical conditioning procedure in which a stimulus was made either a CS + or a CS - with respect to responseindependent food. In the second phase, the subjects were presented a light-dark discrimination in a T-maze in which the CS + or the CS - was presented in addition to the food reinforcer for a correct choice. Relative to a control condition in which a neutral stimulus was presented, the presentation of the $\mathrm{CS}+$ retarded the acquisition of the discrimination (a blocking effect) and presentation of the CS facilitated the discrimination ("superconditioning"). Of greater interest was the finding (Fowler, Goodman, \& Zanich, 1977) that blocking and facilitation effects also occurred, but in symmetrically opposite directions, when the first phase of training involved shock instead of food. That is, the CS - with respect to shock retarded the light-dark appetitive discrimination, whereas the CS + with respect to shock facilitated the discrimination.

It can be argued that the present study is still fundamentally different from those reported by Fowler and his colleagues (and from previous classical conditioning studies), because the present study involved not the acquisition of new learning but the modulation of the level of responding after acquisition had occurred. Such a distinction is in keeping with the assumption implicit in much recent theorizing that the determinants of acquisition and "steady-state" behavior are fundamentally different (e.g., Staddon \& Simmelhag, 1971). It should be noted, however, that the most prominent interpretation of blocking effects (Rescorla \& Wagner, 1972) does imply that blocking should occur with steadystate training procedures as well. This can be illustrated by several studies (Kamin \& Gaioni, 1974; Rescorla, 1970; Wagner, 1971) in which subjects were trained to asymptote with each of two stimuli independently, and then pairing with the reinforcer was continued with the two stimuli presented in compound. The results of the compound training were that responding evoked by each element in isolation decreased. The reason for this result, according to the Rescorla-Wagner model, is that the reinforcer can support only a fixed amount of response strength and this amount is less than the sum of the response strengths conditioned to the two stimuli after each has been trained separately.

The same analysis should also apply to the procedure used in the present study. Reinforcement that occurred on trials involving the delay-of-reinforcement contingency supported two types of responding: the instrumental response that produced the delayed reinforcer (pecks to the left key) and the behavior evoked by the $\mathrm{S}+$ preceding the reinforcer's delivery. Because the behavior controlled by the interpolated $\mathrm{S}+$ was also maintained by reinforcement on trials not involving the delayed-reinforcement contingency, response strength to the $\mathrm{S}+$ was always near its asymptotic value. Consequently, if, at the beginning of training, the response strength to the left key was also high, the sum of response strengths to the left key and to the $S+$ would be greater than the asymptotic response strength possible. Thus, the strength of responding controlled by both stimuli should decline. But while the $S+$ had its response strength continuously increased on trials in which it was presented alone, response strength to the left key depended solely on the trials in which the left key and the $\mathrm{S}+$ both occurred. The result thus should be that responding to the left key should progressively decrease regardless of the level at which it began.

Perhaps the most important aspect of the present results is their implication for the concept of response strength itself. Experiment 2 demonstrated that keypecking to the left key was attenuated by the interpolation of the tone $\mathrm{S}+$ during the delay-ofreinforcement interval, in spite of the fact that the tone itself did not elicit keypecking behavior. This is important because, as noted above, the RescorlaWagner analysis of blocking implies that blocking should occur when the sum of the response strengths to the left key and to the interpolated $\mathrm{S}+$ is greater than the asymptotic strength possible. This implies, in turn, that some scale of response strength must be applicable to both the behavior evoked by the keylight and the behavior evoked by the tone, in spite of that fact that the topography of responding to the stimuli was different. Similar effects have been reported in classical conditioning experiments (cf. Holland, 1977) where the pretrained stimulus causing the blocking did not itself elicit the behavior being conditioned. Taken together with the present study, these results imply that it is the "associative value" of a stimulus (the extent to which it predicts the reinforcer) that will determine blocking effects, with the particular behavior controlled by the stimulus (whether operant or respondent) being largely irrelevant.

\section{REFERENCE NOTE}

1. Lolordo, V. M., Jacobs, W. J., \& Foree, D. D. Failure to block control to a relevant stimulus. Paper presented at Psychonomic Society meetings in Denver, November 1975.

\section{REFERENCES}

Foree, D. D., \& Lolordo, V. M. Signalled and unsignalled freeoperant avoidance in the pigeon. Journal of the Experimental Analysis of Behavior, 1970, 13, 283-290.

ForeE, D. D.. \& Lolordo, V. M. Attention in the pigeon: The differential effect of food getting vs. shock avoidance procedures. Journal of Comparative and Physiological Psychology. 1973. 85. 551-558.

Fowler. H. Cognitive associations as evident in the blocking effects of response-contingent CSs. In S. Hulse. H. Fou'ler, \& 
W. Honig (Eds.), Cognitive processes in animal behavior. Hillsdale, N.J: Erlbaum, in press.

Fowler, H., Goodman, J., \& Zanich, M. Pavlovian aversive to instrumental appetitive transfer: Evidence for acrossreinforcement blocking effects. Animal Learning \& Behavior, $1977,5,129.134$.

GHISELLI, W. B., \& Fowler, H. Signaling and affective functions of conditioned aversive stimuli in an appetitive choice discrimination: US intensity effects. Learning and Motivation, 1976, 7, $1-16$.

Hearst, E., \& Jenkins, H. M. Sign-tracking: The stimulusreinforcer relation and directed action. Austin, Tx: Psychonomic Society, 1974.

Hemmes, N. Behavioral contrast in pigeons depends upon the operant. Journal of Comparative and Physiological Psychology, $1973,85,171-178$.

Holland, P. C. Conditioned stimulus as a determinant of the form of the Pavlovian conditioned response. Journal of Experimental Psychology: Animal Behavior Processes, 1977, 3, 77-104.

Kamin, L. J. Predictability, surprise, attention, and conditioning. In B. Campbell \& R. Church (Eds.), Punishment and aversive behavior. New York: Appleton-Century-Crofts, 1969.

Kamin, L. J., \& Gaioni, S. J. Compound conditioned emotional response conditioning with differentially salient elements in rats. Journal of Comparative and Physiological Psychology, 1974, 87, 591-597.

Mackintosh. N. J. A theory of attention: Variations in the associability of stimuli with reinforcement. Psychological Review, 1975, 82, 276-298.

Moore, B. R. The role of directed Pavlovian reactions in simple instrumental learning in the pigeon. In R. Hinde \& J. S. Hinde (Eds.). Constraints on learning. New York: Academic Press, 1973. Pp. 159-186.
RESCORLA, R. Reduction in the effectiveness of reinforcement after prior excitatory conditioning. Learning and Motivation, 1970, 1 , $372-381$.

Rescorla, R. A., \& W Agner, A. R. A theory of Pavlovian conditioning: Variations in the effectiveness of reinforcement and nonreinforcement. In A. H. Black \& W. F. Prokasy (Eds.), Classical condition II: Current research and theory. New York: AppletonCentury-Crofts, 1972.

Schwartz, B., \& Gamzu, E. Pavlovian control of operant behavior: An analysis of autoshaping and its implications for operant conditioning. In W. Honig \& J. Staddon (Eds.), Handbook of operant behavior. New York: Prentice-Hall, 1977.

Spence, K. W. Behavior theory and conditioning. New Haven, Conn: Yale University Press, 1956.

Staddon, J. E. R., \& Simmelhag, V. L. The "superstition" experiment: A re-examination of its implications for the principles of adaptive behavior. Psychological Review, 1971, 78, 3-43.

W AGNER, A. R. Elementary associations. In H. Kender \& J. Spence (Eds.), Essays in neo-behaviorism: A memorial volume to Kenneth W. Spence. New York: Appleton-Century-Crofts, 1971.

WEstrRoor, R. F. Failure to obtain positive contrast when pigeons press a bar. Joumal of the Experimental Analysis of Behavior, 1973, 20, 499-510.

Williams, B. A. The blocking of reinforcement control. Journal of the Experimental Analysis of Behavior, 1975, 24, 215-225.

Williams, D. R., \& Williams, H. Auto-maintenance in the pigeon: Sustained pecking despite coutingent nonreinforcement. Journal of the Experimental Analysis of Behavior, 1969, 12. 511-520.

(Received for publication November 15, 1977; revision accepted April 26, 1978.) 